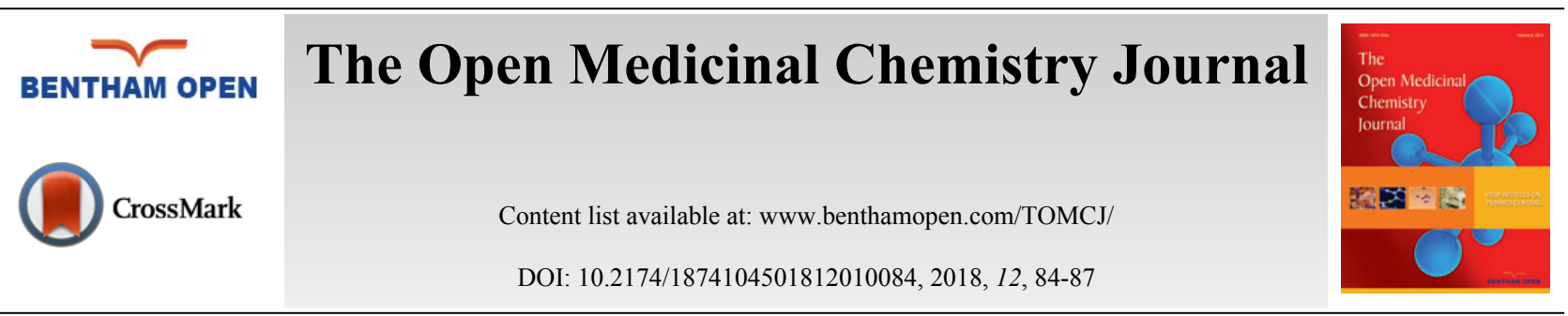

EDITORIAL

\title{
Bacterial Biofilm Inhibition in the Development of Effective Anti- Virulence Strategy
}

There is an urgent need for new therapeutic strategies to counteract the global threat of antibiotic resistance, which has become, in recent years, one of the major public health concern [1].

An important contribution to the microbial survival in hostile environments has been given by the capability of pathogens to form sessile communities able to adhere to biotic or abiotic surfaces, known as biofilms [2].

In biofilms microbial cells are embedded in a self-synthesized matrix consisting of extracellular polymeric substance (EPS) formed by polysaccharides, proteins, lipids and extracellular DNA (e-DNA) as well as molecules originating from the host, such as mucus and DNA [3].

It was observed that bacterial cells inside the biofilm are thousand times more resistant to the conventional antibiotics than the free-living forms [4]. The biofilm antibiotic resistance is correlatable to various mechanisms involved in both cellular and community level, including, at cellular level, enzymatic resistance, chemical modification of the antibiotic target and changes in cell permeability whereas, at biofilm level, the limited penetration of the antibiotic and the presence in the deepest layers of dormant cells intrinsically resistant to conventional antibiotic treatments $[5,6]$.

Biofilm formation is currently one of the most relevant key virulence factor for Gram-positive and Gram-negative pathogens responsible for serious chronic infections such as chronic wound infections, pneumonia in cystic fibrosis patients, osteomyelitis, and otitis [2, 7].

Despite many efforts have been made with the aim to obtain compounds able to modulate bacterial biofilm life cycle, inhibiting biofilm formation [8 - 11] or dispersing pre-formed biofilms [12], biofilm formation remains the leading cause of antibiotic treatment failure, and biofilm-related infections are extremely challenging to treat [13]. The main shortcomings of scientific research in this field are the lack of in vitro and in vivo studies for clarifying the mechanisms of action and for assessing the clinical potential of the new anti-biofilm compounds.

Contrary to conventional antibiotics, most of the anti-biofilm compounds act as anti-virulence agents as they affect a virulence factor (biofilm) not interfering with the bacterial growth, hence demanding a low selection pressure for the development of antibiotic-resistance mutants.

To date the mechanisms of action of the known anti-biofilm compounds may involve:(i) the inhibition of the bacterial adhesion, which is considered the initial steps in bacterial pathogenesis [6]; (ii) the modulation of the quorum sensing (QS) system [14]; (iii) the interference with the nucleotide second messenger signaling systems [15], and (iv) the disruption of the structure of mature biofilm [12].

Sortase A (SrtA) represents an ideal target for the development of new anti-biofilm agents able to interfere with the bacterial adhesion of important Gram-positive pathogens [16].

SrtA is a transpeptidase responsible for the anchorage of surface proteins, known as microbial surface components recognizing adhesive matrix molecules (MSCRAMMs), to the cell wall envelope of Gram-positive bacteria. Many MSCRAMMs play pitoval roles in the severity of chronic $S$. aureus infections, representative examples are the protein A SpA, the fibronectin binding proteins FnbpA and FnbpB, the clumping factors ClfA and ClfB, the collagen-binding protein Cna and the serine-aspartate repeat proteins SdrC, SdrD, and SdrE [17]. Some of these proteins proved to be 
crucial for the biofilm formation process [18].

This transpeptidase is suitable as target for new anti-virulence agents because it is involved in the bacterial adhesion but is not essential for microbial growth. Additionally, being a membrane enzyme, it is more easily approachable by inhibitors and, considering that eukaryotic cells do not possess enzymes of sortase family, it should be easier to obtain selective inhibitor endowed with a low toxicity [19].

The role of SrtA in the biofilm formation is widely described, the overexpression of SrtA is strictly correlated with the ability of some staphylococcal strains to form biofilm, whereas loss of SrtA in five S. aureus clinical isolates significantly reduced this capability [19].

Other suitable targets to develop an effective anti-virulence strategy are the second messengers cyclic dimeric guanosine monophosphate (c-di-GMP) and the cyclic dimeric adenosine monophosphate (c-di-AMP) which are essential for modulating biofilm formation in many Gram-negative and Gram-positive pathogens [15].

It was reported that small organic molecules targeting c-di-GMP and c-di-AMP -related pathways are able to interfere with biofilm formation and to destroy preformed biofilm through the inhibition of the synthesis of matrix components [20].

Anti-biofilm agents can have different therapeutic application depending on their effects on the biofilm: compounds which interfere with biofilm formation can be exploited in the prophylaxis of implant surgery or for the coatings in medical devices, whereas agents able to disperse biofilm structure could be administered in combination with conventional antibiotics for the treatment of biofilm-associated infections.

Despite the growing number of new potent anti-biofilm compounds described in the past decade, the treatment of serious biofilm-associated infections still remains a significant problem. Unfortunately, no anti-biofilm compound has reached the clinical use and the most promising candidates are still in early stages of drug development, this is mainly due to the lack of in vivo studies [21].

\section{REFERENCES}

[1] Schillaci, D.; Spanò, V.; Parrino, B.; Carbone, A.; Montalbano, A.; Barraja, P.; Diana, P.; Cirrincione, G.; Cascioferro, S. Pharmaceutical approaches to target antibiotic resistance mechanisms. J. Med. Chem., 2017, 60(20), 8268-8297. [http://dx.doi.org/10.1021/acs.jmedchem.7b00215] [PMID: 28594170]

[2] Li, X-H.; Lee, J-H. Antibiofilm agents: A new perspective for antimicrobial strategy. J. Microbiol., 2017, 55(10), 753-766. [http://dx.doi.org/10.1007/s12275-017-7274-x] [PMID: 28956348]

[3] Yang, L.; Liu, Y.; Wu, H.; Song, Z.; Høiby, N.; Molin, S.; Givskov, M. Combating biofilms. FEMS Immunol. Med. Microbiol., 2012, 65(2), $146-157$. [http://dx.doi.org/10.1111/j.1574-695X.2011.00858.x] [PMID: 22066868]

[4] Høiby, N.; Bjarnsholt, T.; Givskov, M.; Molin, S.; Ciofu, O. Antibiotic resistance of bacterial biofilms. Int. J. Antimicrob. Agents, 2010, 35(4), 322-332.

[http://dx.doi.org/10.1016/j.ijantimicag.2009.12.011] [PMID: 20149602]

[5] Sánchez-Romero, M.A.; Casadesús, J. Contribution of phenotypic heterogeneity to adaptive antibiotic resistance. Proc. Natl. Acad. Sci. USA, 2014, $111(1), 355-360$.

[http://dx.doi.org/10.1073/pnas.1316084111] [PMID: 24351930]

[6] Cascioferro, S.; Cusimano, M.G.; Schillaci, D. Antiadhesion agents against Gram-positive pathogens. Future Microbiol., 2014, 9(10), 1209-1220. [http://dx.doi.org/10.2217/fmb.14.56] [PMID: 25405889]

[7] Parsek, M.R.; Singh, P.K. Bacterial biofilms: An emerging link to disease pathogenesis. Annu. Rev. Microbiol., 2003, 57, 677-701. [http://dx.doi.org/10.1146/annurev.micro.57.030502.090720] [PMID: 14527295]

[8] Viszwapriya, D.; Prithika, U.; Deebika, S.; Balamurugan, K.; Pandian, S.K. In vitro and in vivo antibiofilm potential of 2,4-Di-tertbutylphenol from seaweed surface associated bacterium Bacillus subtilis against group A streptococcus. Microbiol. Res., 2016, 191 , 19-31. [http://dx.doi.org/10.1016/j.micres.2016.05.010] [PMID: 27524650]

[9] Cascioferro, S.; Maggio, B.; Raffa, D.; Raimondi, M.V.; Cusimano, M.G.; Schillaci, D.; Manachini, B.; Plescia, F.; Daidone, G. Synthesis and biofilm formation reduction of pyrazole-4-carboxamide derivatives in some Staphylococcus aureus strains. Eur. J. Med. Chem., 2016, 123, 58-68. [http://dx.doi.org/10.1016/j.ejmech.2016.07.030] [PMID: 27474923]

[10] Cascioferro, S.; Maggio, B.; Raffa, D.; Raimondi, M.V.; Cusimano, M.G.; Schillaci, D.; Manachini, B.; Leonchiks, A.; Daidone, G. A new class of phenylhydrazinylidene derivatives as inhibitors of Staphylococcus aureus biofilm formation. Med. Chem. Res., 2016, 25, 870-878. [http://dx.doi.org/10.1007/s00044-016-1535-9] 
[11] Hodnik, Ž.; Łoś, J.M.; Žula, A.; Zidar, N.; Jakopin, Ž.; Łoś, M.; Sollner Dolenc, M.; Ilaš, J.; Węgrzyn, G.; Peterlin Mašič, L.; Kikelj, D. Inhibition of biofilm formation by conformationally constrained indole-based analogues of the marine alkaloid oroidin. Bioorg. Med. Chem. Lett., 2014, 24(11), 2530-2534.

[http://dx.doi.org/10.1016/j.bmcl.2014.03.094] [PMID: 24755428]

[12] Fleming, D.; Rumbaugh, K.P. Approaches to dispersing medical biofilms. Microorganisms, 2017, 5(2), E15. [http://dx.doi.org/10.3390/microorganisms5020015] [PMID: 28368320]

[13] Lebeaux, D.; Ghigo, J-M.; Beloin, C. Biofilm-related infections: Bridging the gap between clinical management and fundamental aspects of recalcitrance toward antibiotics. Microbiol. Mol. Biol. Rev., 2014, 78(3), 510-543. [http://dx.doi.org/10.1128/MMBR.00013-14] [PMID: 25184564]

[14] Geske, G.D.; Wezeman, R.J.; Siegel, A.P.; Blackwell, H.E. Small molecule inhibitors of bacterial quorum sensing and biofilm formation. J. Am. Chem. Soc., 2005, 127(37), 12762-12763. [http://dx.doi.org/10.1021/ja0530321] [PMID: 16159245]

[15] Boyd, C.D.; O’Toole, G.A. Second messenger regulation of biofilm formation: Breakthroughs in understanding c-di-GMP effector systems. Annu. Rev. Cell Dev. Biol., 2012, 28, 439-462. [http://dx.doi.org/10.1146/annurev-cellbio-101011-155705] [PMID: 23057745]

[16] Cascioferro, S.; Totsika, M.; Schillaci, D.; Sortase, A. Sortase A: An ideal target for anti-virulence drug development. Microb. Pathog., 2014, $77,105-112$. [http://dx.doi.org/10.1016/j.micpath.2014.10.007] [PMID: 25457798]

[17] Nandakumar, R.; Nandakumar, M.P.; Marten, M.R.; Ross, J.M. Proteome analysis of membrane and cell wall associated proteins from Staphylococcus aureus. J. Proteome Res., 2005, 4(2), 250-257. [http://dx.doi.org/10.1021/pr049866k] [PMID: 15822900]

[18] Tsompanidou, E.; Denham, E.L.; Sibbald, M.J.J.B.; Yang, X-M.; Seinen, J.; Friedrich, A.W.; Buist, G.; van Dijl, J.M. The sortase A substrates FnbpA, FnbpB, ClfA and ClfB antagonize colony spreading of Staphylococcus aureus. PLoS One, 2012, 7(9), e44646. [http://dx.doi.org/10.1371/journal.pone.0044646] [PMID: 22970276]

[19] Cascioferro, S.; Raffa, D.; Maggio, B.; Raimondi, M.V.; Schillaci, D.; Daidone, G.; Sortase, A. Sortase a inhibitors: Recent advances and future perspectives. J. Med. Chem., 2015, 58(23), 9108-9123. [http://dx.doi.org/10.1021/acs.jmedchem.5b00779] [PMID: 26280844]

[20] Sambanthamoorthy, K.; Sloup, R.E.; Parashar, V.; Smith, J.M.; Kim, E.E.; Semmelhack, M.F.; Neiditch, M.B.; Waters, C.M. Identification of small molecules that antagonize diguanylate cyclase enzymes to inhibit biofilm formation. Antimicrob. Agents Chemother., 2012, 56(10), $5202-5211$.

[http://dx.doi.org/10.1128/AAC.01396-12] [PMID: 22850508]

[21] Rabin, N.; Zheng, Y.; Opoku-Temeng, C.; Du, Y.; Bonsu, E.; Sintim, H.O. Agents that inhibit bacterial biofilm formation. Future Med. Chem., 2015, 7(5), 647-671. [http://dx.doi.org/10.4155/fmc.15.7] [PMID: 25921403]

Barbara Parrino

Dipartimento di Scienze e Tecnologie Biologiche

Chimiche e Farmaceutiche

Sezione di Chimica e Tecnologie Farmaceutiche Università degli Studi di Palermo

Via Archirafi 32

90123, Palermo

Italy

Patrizia Diana

Dipartimento di Scienze e Tecnologie Biologiche

Chimiche e Farmaceutiche

Sezione di Chimica e Tecnologie Farmaceutiche

Università degli Studi di Palermo

Via Archirafi 32

90123, Palermo Italy

Girolamo Cirrincione

Dipartimento di Scienze e Tecnologie Biologiche

Chimiche e Farmaceutiche 
Sezione di Chimica e Tecnologie Farmaceutiche Università degli Studi di Palermo

Via Archirafi 32

90123, Palermo

Italy

Stella Cascioferro

Dipartimento di Scienze e Tecnologie Biologiche

Chimiche e Farmaceutiche

Sezione di Chimica e Tecnologie Farmaceutiche

Università degli Studi di Palermo

Via Archirafi 32

90123, Palermo

Italy

E-mail: stellamaria.cascioferro@unipa.it

\section{(C) 2018 Parrino et al.}

This is an open access article distributed under the terms of the Creative Commons Attribution 4. 0 International Public License (CC-BY 4. 0), a copy of which is available at: https://creativecommons. org/licenses/by/4. 0/legalcode. This license permits unrestricted use, distribution, and reproduction in any medium, provided the original author and source are credited. 